\title{
Disidencias sexo-genéricas en dos textos dramáticos del siglo XX argentino ${ }^{1}$
}

\author{
Jorge Luis Peralta \\ Universidad Nacional de La Pampa
}

Aunque se hayan consagrado muchos estudios a las figuraciones del homoerotismo en la narrativa argentina, otros géneros literarios, como el teatro o la poesía, no han sido objeto del mismo interés. Una de las excepciones, el drama realista Los invertidos, de José González Castillo (1885-1937), estrenado y publicado en 1914, constituye un caso pionero, no solo de la escena argentina, sino de la hispanoamericana en su conjunto, hecho que explica los diversos acechos críticos que ha merecido, así como las numerosas reediciones y representaciones ${ }^{2}$. En estas páginas me interesa abordar el texto de González Castillo para confrontarlo con otro menos conocido y estudiado: la comedia El alba sobre Sodoma de Pedro Badanelli (1899-1985), publicada en 1969³. Dado que hasta la década de los 70, estas fueron prácticamente las únicas piezas teatrales argentinas que re-

1. Este trabajo forma parte del proyecto FEM2015-69863-P MINECO-FEDER.

2. A la edición original en Prensa Moderna, de 1914, le siguieron las de Editorial Carro de Tespis (1957), Puntosur (1991), Razón y Revolución (2011), Losada (2014) y Corregidor (2015). En cuanto a las representaciones, la primera, de 1914, a cargo de la compañía Podestá-Ballerini, fue prohibida tras 9 funciones por considerarse que atentaba contra la moral y las buenas costumbres. Volvió a estrenarse en 1956, bajo la dirección de Homero Cárpena, y fue nuevamente censurada. La siguiente puesta, de Alberto Ure, se estrenó en 1990. Entre las versiones más recientes se encuentran las de Rody Bertol (2007-2008), Mariano Dossena (2011 y 2017), Tomás Turderos (2016), Victor Cano Ayerra (2016) y Guillermo Troncoso (2018).

3. De acuerdo con Pedro Monge Rafuls ("Notas incompletas sobre un teatro desconocido", Ollantay Theather Magazine, vol. XV, n. 29-30, p. 121), la obra fue representada por la compañía de Horacio Ferrari el 2 de julio de 1970 en el Teatro 35 de Buenos Aires. 
presentaron explícitamente identidades sexo-genéricas disidentes ${ }^{4}$, resultan testimonios de indudable valor para considerar los modos en que pudieron articular la puesta en discurso de una sexualidad proscrita tanto en la órbita social como en la literaria. El hecho de que se publicaran y representaran, además, con medio siglo de diferencia, permite valorar las transformaciones ocurridas, entre una y otra, con respecto a la percepción y autopercepción de subjetividades homoeróticas en el espacio teatral.

Las obras de González Castillo y Badanelli oscilan entre las interpretaciones oficiales acerca de la "homosexualidad" y tímidas — y no tanto — vindicaciones de la disidencia: así, el primero refrenda, por un lado, el paradigma médico-psiquiátrico de su tiempo, a la vez que deja un margen de subversión para algunos de sus "invertidos"; mientras que el segundo, a contrapelo de la mayoría de discursos coetáneos, presenta una apología de la "homosexualidad" en sintonía con otros trabajos suyos de carácter ensayístico. Ambos textos, siguiendo las convenciones del teatro de tesis, en general, y de sus respectivos subgéneros, se hacen eco de una realidad socio-sexual contemporánea al momento de la escritura y representación; funcionan, en este sentido, como caja de resonancia de fenómenos significativos de sus respectivos contextos: la aparición de nuevas subjetividades en el Buenos Aires de comienzos del siglo XX en Los invertidos; la consolidación de una subcultura y su inminente politización hacia los años 60 en El alba sobre Sodoma.

\section{Contrapuntos DEL DisCURSO MÉDICO-PSIQUiÁtrico EN LOS INVERTIDOS}

Entre las últimas décadas del siglo XIX y las primeras del $\mathrm{xx}$, una serie de cambios demográficos, económicos y sociales favorecieron la emergencia de nuevas subjetividades sexo-genéricas en la ciudad de Buenos Aires. La inmigración masiva que comenzó a ingresar al país desde la década de 1880 modificó las características del espacio — que, a inusual velocidad, pasó de ser "gran aldea" a "metrópoli" — y de la población que lo habitaba: la desproporcionada cantidad de varones, en su mayoría jóvenes inmigrantes, favoreció relaciones que oscilaban entre la homosociabilidad y el homoerotismo ${ }^{5}$. El universo de "invertidos" que formó parte del paisaje social de la ciudad durante esa época constituye la principal referencia del drama de González Castillo ${ }^{6}$. Aunque algunos

4. Las otras dos fueron La lombriz de Julio Imbert, representada en 1951, pero que permanece inédita y a la que no he tenido acceso, y Ser un hombre como tú (1957) de Juan Arias, centrado en la reacción homofóbica del protagonista cuando descubre que su hermano es homosexual. Este foco propicia que la pieza de Arias ofrezca menos aristas para un análisis de los discursos homosexuales.

5. Cf. Pablo Ben, Male Sexuality, the Popular Classes and the State: Buenos Aires, 1880-1955, University of Chicago, Chicago, 2009.

6. González Castillo se cuenta entre los dramaturgos más prominentes de la primera mitad del siglo XX en Argentina, además de compositor de tangos y guionista de cine. Sin embargo, como señala Osvaldo 
investigadores, como Jorge Salessi ${ }^{7}$, se hayan focalizado en los discursos patologizadores de la élite científica, empeñada en identificar y describir las conductas sexuales que se apartaban de la "normalidad", otros estudiosos, como Pablo Ben, han adoptado la perspectiva de la historia social con el objetivo de reconstruir las prácticas sexo-genéricas efectivas, especialmente de las clases populares, que, según demuestra, pudieron desarrollarse al margen de los esfuerzos clasificatorios de médicos y criminólogos: no existía, en rigor, una legislación específica que persiguiera y condenara la "homosexualidad"8. De acuerdo con este investigador, las "maricas" de las clases populares no poseían su propia subcultura, sino que se integraban en el amplio "bajo fondo" de delincuencia y prostitución que imperaba en Buenos Aires durante el periodo. Estas "maricas" se caracterizaban por adoptar nombres, modales y vestimenta femeninas y su performance de género podía ser más desprejuiciada y "escandalosa" que la de los "invertidos" de clases sociales más altas, quienes, si bien disfrutaban de ciertas ventajas — como estar al margen de la vigilancia médico-policial—, se veían obligados a respetar determinados códigos de conducta.

González Castillo recrea todos estos aspectos del submundo de "maricas" e "invertidos" porteños y reproduce, consecuentemente, el discurso médico-psiquiátrico que, desde finales del siglo XIX, venían elaborando personalidades como José María Ramos Mejía, Francisco de Veyga y Eusebio Gómez, entre otros. El aspecto que interesa señalar aquí es el modo como este discurso se modula - y resulta significativamente contradicho- a través de los personajes de los "invertidos", sobre todo de las clases populares. El argumento del drama, conviene recordar, gira en torno a dos sujetos de buena posición social, Flórez y Pérez, quienes mantienen una relación oculta desde la adolescencia. Cuando Clara, mujer de Flórez, descubre la relación entre los hombres, mata a Pérez y obliga a su marido a suicidarse. Otros personajes relevantes son las "maricas" plebeyas, Princesa de Borbón, Juanita y Emilio, quienes asumen protagonismo durante el segundo acto, mientras esperan a Flórez y Pérez para una reunión que nunca llega a producirse.

El discurso que plantea la obra no es, exactamente, acerca de la "homosexualidad" sino de la "inversión sexual", una de las categorías que preceden, según David Halperin, la noción más moderna de "homosexualidad". La característica distintiva de la "inversión" es la desviación de género sexual: se "invierte", de acuerdo con esta teoría, la

Pelletieri, "su producción dramática, constituida por más de ochenta obras, espera todavía ser evaluada, clasificada y ubicada con profundidad en nuestro sistema teatral” "José González Castillo: práctica y teoría teatral", Escena y realidad, ed. O. Pelletieri, Galerna-Universidad de Buenos Aires, Buenos Aires, 2003, p. 221). A esa labor ha contribuido recientemente el estudio de Mónica Villa (José González Castillo. Militante de lo popular, Corregidor, Buenos Aires, 2015).

7. Médicos maleantes y maricas. Higiene, criminología y homosexualidad en la construcción de la Nación Argentina (1871-1914), Beatriz Viterbo, Rosario, 1995.

8. Políticamente, el país se encontraba bajo el gobierno democrático-liberal de Roque Sáenz Peńa, cuyo mandato se extendió entre 1910 y 1914.

9. How to Do the History of Homosexuality, University of Chicago, Chicago, 2002, pp. 104-137. 
identidad genérica correspondiente al sexo biológico del sujeto. Esta infracción puede ir acompañada, o no, de una elección de objeto del mismo sexo. Los médicos, psiquiatras y criminólogos argentinos diferenciaban, siguiendo a autores extranjeros, entre la "inversión sexual congénita" y la "inversión sexual adquirida". Cada una de estas explicaciones se vinculaba con una clase social determinada: los "invertidos congénitos" eran plebeyos, sobre todo inmigrantes; los que "adquirían" la inversión pertenecían a las clases acomodadas. Un ejemplo de este discurso médico-psiquiátrico oficial aparece al inicio del primer acto, cuando Julián, hijo de Flórez, lee un informe pericial redactado por su padre — médico legalista — acerca de un "hermafrodita" asesino:

No aparecen en él, después de un prolijo estudio orgánico, las deformaciones fisiológicas que a tales casos, por excepción, caracterizan y que inspiró a los griegos el mito de Hermafrodita, pero sus hábitos, marcadamente femeninos, las sutilezas de su idiosincrasia, [...] la inflexión de su voz, suave y acariciadora, la misma constante manifestación de vagas coqueterías femeninas, nos hacen pensar en que estamos en presencia de uno de esos extraños fenómenos de desdoblamiento sensual, que, más que a una aberración del sexo, obedecen a una perversión del instinto, aguzada por el exceso de los placeres, la fragilidad de una insuficiente educación físico-moral y aun quizás, por las tendencias ancestrales de una herencia morbosa ${ }^{10}$.

En sintonía con los argumentos de la ciencia coetánea, el informe de Flórez describe la inversión como "perversión del instinto", diferenciando así entre este caso y otros en que la inversión era el resultado de un carácter moralmente depravado - como el que encarna en la obra el personaje de Pérez-. Ahora bien, hay que destacar que este informe, si bien patologiza, al mismo tiempo disculpa, al menos en parte, al sujeto en cuestión, al señalar que padece una condición patológica. Esta disculpa resulta estratégica, pues es el propio Flórez quien ha redactado el texto y el caso que describe se asemeja al suyo; no casualmente, ante las protestas horrorizadas de su esposa, el personaje declarará "una extraña simpatía, una especie de misericordiosa lástima por todos esos infelices"11. Que ese discurso opera, en realidad, como fachada de un universo secreto queda al descubierto en una escena posterior del mismo acto, cuando Flórez recibe la visita de su amante, Pérez, y un amigo de ambos, Fernández: en ese momento el público toma conocimiento de que estos varones de buena posición social son "invertidos" y pertenecen a una especie de club al que llaman "cofradía" y en el que se relacionan con otros varones de su misma preferencia erótica, incluyendo sujetos de clases sociales más bajas ${ }^{12}$. En un nuevo giro discursivo, se observa que Flórez y el resto de "cofrades" distan de identifi-

10. José González Castillo, Los invertidos, Corregidor, Buenos Aires, 2015, p. 34.

11. Los invertidos, p. 43.

12. Para una descripción contemporánea de las "cofradías", cf. Eusebio Gómez (La mala vida en Buenos Aires, Juan Roldán, Buenos Aires, 1908, pp. 191-192). 
carse con los severos postulados de la ciencia; por el contrario, parecen muy cómodos con su condición sexual y utilizan un lenguaje generoso en códigos y sobreentendidos. Por ejemplo, cuando conversan a propósito del duelo que Fernández le propuso a otro "cofrade" (que osó tratarlo públicamente de "maricón") aluden de forma explícita a sus preferencias en materia de posiciones sexuales:

FLÓREZ: [...] Y pasando al asunto... ¿ ¿No te sería lo mismo batirte a pistola que a sable?

FERNÁNDEZ: Sí, para mí es lo mismo...

PÉREZ: Es que el sable... lo maneja mejor el otro... Pega cada sablazo...

FERNÁNDEZ: Porque es de los tuyos...

PÉREZ: ¡Qué quieres...! ¡Pertenecemos a la plana activa! ${ }^{13}$

La distancia entre el tono dramático del informe con el que se inicia la obra y estos parlamentos, jugados en clave de comedia, resulta evidente. Afirmar la intencionalidad homofóbica de la pieza supone pasar por alto que en su complejo ensamblaje discursivo se cruzan voces y mensajes antitéticos, que responden a concepciones muy diferentes del género y la sexualidad. Son, sin embargo, las "maricas" plebeyas que asumen protagonismo durante el segundo acto, las que ponen verdaderamente en entredicho los postulados de la ciencia. Dado que, a diferencia de Flórez y Pérez, ellas no deben observar un código de conducta ni "mantener las apariencias", pueden permitirse ejercer una disidencia sexo-genérica mucho más desprejuiciada:

JUANITA: ¡Ay! ¡Quién hubiera nacido hombre!

PRINCESA: ¡Ay! ¡Quién hubiera nacido mujer!, decí mejor.

EMILIO: No se quejen, que no tienen razón. Al fin y al cabo mejor que ser hombre o mujer solamente, es ser las dos cosas a la vez, y ustedes no se pueden quejar.

En las antípodas de las teorías elucubradas por la élite médico-psiquiátrica, estas "maricas" configuran un discurso que cuestiona el carácter estable del género y la sexualidad: muestran, de hecho, que las fronteras son porosas y, por lo tanto, inestables. Su actitud evoca los testimonios que, de manera coetánea, recolectaban médicos y criminólogos, y que desafiaban abiertamente su esfuerzo por identificar y caracterizar los comportamientos sexo-genéricos "desviados". La fluidez con que estos sujetos vivían su sexualidad difícilmente podía acomodarse en los rígidos modelos teóricos elaborados por la ciencia.

La lectura atenta permite confirmar, en definitiva, que en la obra colisionan las concepciones médico-psiquiátricas en torno a la "inversión sexual" — proyectadas sobre los personajes burgueses con el objetivo de denunciar su hipocresía- y una visión más fluida y desestructurada del género y la sexualidad que emana de los personajes plebeyos,

13. Los invertidos, p. 48. 
quienes no reciben ninguna clase de castigo. La intención moralizante que el propio autor defendió cuando la pieza fue censurada resulta socavada por las potencias disidentes que desatan estas "maricas" desde el momento mismo en que entran en escena: el hecho de que lo hagan bailando un tango — según indican las didascalias - refuerza su capacidad de perturbar los binarismos de sexo-género. Haciéndose eco de la realidad inmediata, el texto acaba por desdoblarse: una parte de su discurso se dirige a denunciar la decadencia moral de las clases dominantes (en sintonía con la ideología anarquista del autor), mientras que la otra descubre un submundo en el que las normas no parecen tener el mismo valor. La calle se apodera de la obra en las escenas protagonizadas por las "maricas", produciendo un desequilibrio que bien pudo haber tenido, en el momento del estreno, un efecto perturbador sobre los espectadores: quizá fue ese el motivo más poderoso para la censura, ya que el trágico final reservado a los "invertidos" burgueses seguía las prescripciones de rigor a la hora de representar al personaje homosexual. $\mathrm{Al}$ captar ese submundo eminentemente urbano con sus figuras y prácticas disidentes, González Castillo adelantó, además, muchos elementos del teatro argentino queer posterior, con Copi (1939-1987) como primera e insoslayable referencia ${ }^{14}$.

\section{Apología del 'Homosexualismo’ en EL ALBA SOBRE SODOMA}

A diferencia de Los invertidos, que ocupa un espacio de indudable relevancia en el canon de la literatura argentina de temática homoerótica, El alba sobre Sodoma constituye un eslabón que podría considerarse "perdido" 15 , ya que no se encuentran referencias a esta obra ni a su autor, el español Pedro Badanelli, en la abundante bibliografía disponible sobre literatura y cultura disidentes en el país ${ }^{16}$. Ese vacío puede explicarse, en buena medida, por el hecho de que los textos de Badanelli aparecieron en ediciones financiadas por el propio escritor que hoy resultan inhallables, y que incluso en el momento de su

14. Cf. Diego Trerotola, "Transgénero criollo", Suplemento Soy, 18 de marzo de 2011, en línea.

15. La pieza ha sido analizada, por ejemplo, en las monografías de Adrián Melo (Historia de la literatura gay en Argentina. Representaciones sociales de la homosexualidad masculina en la ficción literaria, Lea, Buenos Aires, 2011, pp. 92-104) y Jorge Luis Peralta (Paisajes de varones. Genealogías del homoerotismo en la literatura argentina, Icaria, Barcelona, 2017, pp. 53-83). Dentro de la bibliografía específicamente teatral, destacan los estudios de Gustavo Geirola ("Sexualidad, anarquía y teatralidad en Los invertidos de González Castillo", Latin American Theatre Review, 28.1 (1995), pp. 73-84), David William Foster ("Consideraciones en torno al homoerotismo en el teatro argentino", Tradición, modernidad y posmodernidad (Teatro argentino e iberoamericano), ed. Osvaldo Pelletieri, Galerna-Universidad de Buenos Aires, Buenos Aires, 1999, pp. 239-244) y Ben de Witte ("Historizing the 'Traveling' Queer Theatricalities of González Castillo's Los invertidos", Theatre Research International, 40.1 (2015), pp. 79-82).

16. Se trata del único texto dramático publicado por Badanelli, cuya ecléctica producción literaria incluye además poesía, narrativa y ensayo. 
publicación debieron circular en un circuito muy acotado. Desconocido en Argentina, donde residió desde la década de 1930 hasta su muerte, el autor tampoco goza de reconocimiento en España: recién en 2016 volvió a editarse una obra suya, la novela Serenata del amor triunfante (1929), otra pieza prácticamente desconocida de la literatura homoerótica de comienzos del siglo XX en lengua española ${ }^{17}$.

El alba sobre Sodoma apareció en un contexto muy diferente al de Los invertidos. El año en que vio la luz, 1969, fue especialmente significativo en la historia de las minorías sexuales, pues en esa fecha se produjeron las célebres revueltas de Stonewall en Nueva York, germen del movimiento de liberación cuyas ondas se expandirían por muy diversas latitudes. Argentina no fue la excepción: ya desde 1967 existía una agrupación, llamada "Nuestro Mundo", cuyos miembros — obreros y militantes de izquierda - se unirían más tarde con un grupo de intelectuales y universitarios para formar el "Frente de Liberación Homosexual” (1971-1976). La percepción y auto-percepción de los hombres que se relacionaban con otros hombres se habían ido modificando en el curso de las décadas. De acuerdo con Omar Acha, "la definición social y cultural de los homosexuales varones coaguló durante el primer peronismo debido a una diversidad de motivos" ${ }^{18}$; sería recién a partir de este momento cuando los varones que se relacionaban con otros varones comenzaron a constituir un grupo diferenciado. Así podría explicarse, también, la emergencia de discursos en primera persona, a través, por ejemplo, de la narrativa de Carlos Correas y Renato Pellegrini ${ }^{19}$. Dentro del ámbito específicamente teatral, Ezequiel Lozano señala que en 1969 "el medio artístico experimenta la eclosión de diferentes discursos teatrales que le dan voz a la disidencia sexual. El grado de visibilidad que la diversidad sexual alcanza en ese momento resulta inédito para la historia del teatro en Buenos Aires" ${ }^{\prime 2}$. Esto no implica, desde luego, un cambio sustancial en los discursos oficiales sobre género y sexualidad. Entre los años 50 y 70 se publicaron en el país numerosos ensayos y manuales divulgativos, la mayoría de los cuales tendían a la patologización y estigmatización de sujetos y conductas homosexuales.

El alba sobre Sodoma viene a inscribirse, en este panorama, como una auténtica rareza que desafía los argumentos religiosos y médicos en contra de la "homosexualidad". Conviene tener en cuenta que en 1950 se le habían retirado al autor sus órdenes ministeriales como sacerdote ${ }^{21}$; su cercanía con el gobierno de Juan Domingo Perón, con cuyo apoyo pretendía liderar una Iglesia Apóstolica No Romana, así como su oposición a la jerarquía

17. Cf. Noel Valis, "Pedro Badanelli's Serenata del amor triunfante, or Gay Love in 1929", ALEC, 41.4 (2016), pp. 301-323.

18. Crónica sentimental de la Argentina peronista. Sexo, inconsciente e ideología, 1945-1955, Prometeo, Buenos Aires, 2013, p. 235.

19. Cf. Jorge Luis Peralta, La ciudad amoral. Espacio urbano y disidencia sexual en Renato Pellegrini y Carlos Correas, Villa María, EDUVIM, 2019 (en prensa).

20. Sexualidades disidentes en el teatro en Buenos Aires durante los años sesenta, Universidad de Buenos Aires, Buenos Aires, p. 10.

21. José C. García Rodríguez, Pedro Badanelli. El presbitero de Perón, RD Editores, Sevilla, 2014, p. 72. 
eclesiástica, se hicieron manifiestas, respectivamente, en Perón, la Iglesia y un cura (1959) y Carta abierta a Paulo VI (1973). Este desentendimiento con la institución católica explica que su discurso en torno a la sexualidad en general y al "homosexualismo" en particular se aparte de los lineamientos defendidos por la iglesia. El libro El derecho penal en la Biblia. Los grandes delitos sexuales. El onanismo, el aborto, la homosexualidad, de 1957, anticipa muchas de las hipótesis que Badanelli retomaría después en El alba sobre Sodoma. Pese a lo que pueda sugerir el título, se trata de una reinterpretación sui generis de las Sagradas Escrituras que pretende poner en evidencia su influencia negativa en el campo del derecho penal, concretamente en lo que concierne a temas sexuales ${ }^{22}$.

El texto dramático de 1969 defiende argumentos similares a los de aquel ensayo a través de la historia de Julito, un joven homosexual de clase alta venida a menos que debe hacer frente al férreo rechazo de su madre, Doña Laura. El conflicto se produce cuando Julito pide permiso a su madre para hacer un viaje con su "amigo íntimo" Leopoldo Schmith, acaudalado hombre mayor. Dońa Laura no autoriza el viaje, pero decide consultar a un médico psiquiatra, quien no solo le recomienda dejar de lado sus prejuicios y aceptar a Julito, sino que además le sugiere consentir la relación de este con Leopoldo, pues podría beneficiar económicamente a la familia. En el acto final, Julito y sus amigos se enteran de que el avión en el que viajaba Leopoldo se ha estrellado. Julito confiesa, además, que su amante, temeroso de que pudiera pasarle algo malo, había firmado a su nombre un seguro millonario. En ese momento aparece Dońa Laura, arrepentida. Julito se niega, sin embargo, a emplear el dinero heredado para sí mismo o su familia. Decide, en cambio, que lo invertirá en la fundación de una cátedra destinada a educar, especialmente a padres y madres, en materia de sexualidad, sin "telarańas escolásticas que intoxiquen de prejuicios y de estupideces ni a los profesores ni a los alumnos" ${ }^{23}$. Un objetivo bastante improbable, por cierto, en la Argentina de 1969, todavía bajo el gobierno militar de Juan Carlos Onganía (1966-1970).

Como en Los invertidos, El alba sobre Sodoma incluye un portavoz de la ciencia, el médico psiquiatra Gerardo Noli, responsable del prólogo con que se inicia la obra. A diferencia del informe que abría el drama de González Castillo y que apuntaba a patologizar la inversión sexual, este texto, abundante en metáforas, no menciona explícitamente la "homosexualidad", pero adelanta la intención de la comedia de rebatir concepciones del hombre y de la mujer "impregnadas [...] de toda desgracia de engañifas y supercherías" 24 . El prólogo podría comprenderse como una especie de captatio benevolentiae que busca predisponer al público a aceptar las audaces hipótesis sobre el "homosexualismo" desarrolladas por el psiquiatra durante el curso del segundo acto, en su consulta con la madre de Julito. Badanelli articula aquí un contra-discurso que invierte la visión dominante:

22. Analizo con más detalle este libro en J. L. Peralta, "Batallas discursivas en torno a la 'homosexualidad' en Argentina (1957-1969)”, Badebec, 7-14 (2018), pp. 67-94.

23. Pedro Badanelli, El alba sobre Sodoma, Biblioteca Privada, Buenos Aires, p. 92.

24. El alba sobre Sodoma, p. 11. 
Usted desearía que yo sometiera a tratamiento a su hijo, sin darse cuenta de que es usted la que necesita ser tratada. Su hijo no tiene ningún problema. Es usted, señora, la que lo tiene, usted que se ha empeńado en no querer entender la sencilla verdad biológica que ofrece el caso de su hijo. Su hijo, no lo dude usted, es feliz, completamente feliz, porque en la gran avanzada de progreso que, pese a tantos prejuicios, hemos llegado, tan solo los uránicos reprimidos viven margados ${ }^{25}$.

El psiquiatra no solo niega enfáticamente que la homosexualidad sea una enfermedad —la presenta como "una modalidad, lo que es muy distinto" 26 _ sino que llega a sugerir que se trata de una condición necesaria frente al problema de la superpoblación. También, en sintonía con un clásico argumento en defensa de los "uranistas", destaca su superioridad artística. Desautorizando, a través de una voz autorizada, los discursos de la Medicina, la Iglesia y la Ley, Badanelli tiende puentes — acaso sin ser consciente de ello- con los movimientos que estaban empezando a surgir contemporáneamente, aunque de manera muy tímida en el caso particular de Argentina, hecho que subraya aún más su carácter pionero.

La obra también evita el discurso culposo y victimista que solía atribuirse a los personajes homosexuales en la literatura en general y el teatro en particular: para limitarse al caso argentino, son ejemplos notorios obras de los años 50 como La lombriz de Julio Imbert y Ser un hombre como tú de Juan Arias, que según Ezequiel Lozano enarbolan un discurso de "asco" hacia las sexualidades disidentes ${ }^{27}$. En la obra de Badanelli, en cambio, los personajes homosexuales articulan una suerte de "orgullo" avant la lettre, como puede apreciarse en el siguiente parlamento del protagonista, Julito:

¿No es verdad que, bien vistas las cosas, el Mundo es nuestro? ¿Cuándo, por ejemplo, nos aburrimos nosotros? Nosotros no nos aburrimos nunca. Siempre hay tela para cortar, y para cortar a carcajadas... porque nuestro mundo es tan pintoresco y tan regocijante que he estado siempre por creer que el odio que nos tienen, o dicen tenernos, los demás, en el fondo no es otra cosa que envidia. Sí, que envidia. Una envidia que ellos no saben explicarse; una envidia por un mundo que no conocen... pero que intuyen, por una especie de misterioso olfato, que debe ser un mundo divertidísimo ${ }^{28}$.

Tal vez se trate de una visión sesgada, en tanto Julito pertenece a una clase social sobre la cual las presiones fueron menos rigurosas: otros testimonios, como el de $\mathrm{Malva}^{29}$, confirman que la situación de los disidentes sexuales de clases medias y bajas estuvo

25. El alba sobre Sodoma, p. 55.

26. El alba sobre Sodoma, p. 66.

27. Sexualidades disidentes en el teatro, pp. 79-89.

28. El alba sobre Sodoma, p. 18.

29. Cf. Malva, Mi recordatorio. Autobiografía de Malva, Libros del Rojas, Buenos Aires, 2010. 
signada, a partir del primer gobierno de Juan Domingo Perón (1946-1955), por la persecución policial y la condena social. No obstante, la actitud desafiante de Julito y sus amigos es indicativa de la pertenencia a una subcultura que favoreció los intercambios homoeróticos y permitió afirmar identidades por fuera del guion heteronormativo. En este sentido, aunque parte del discurso de El alba sobre Sodoma pueda resultar excesivamente optimista leído en su contexto, no es menos cierto que remite a una sociabilidad homosexual documentada en otros textos literarios sobre la misma época, como las novelas La brasa en la mano (1983) de Oscar Hermes Villordo o Plaza de los lirios (1985) de José M. Borghello: la conciencia política que la pieza vislumbra no tardaría en cristalizar y afianzarse, aunque la posterior dictadura militar (1976-1983) abortase los impulsos revolucionarios, circunstancia que demoró, a su vez, cambios más radicales en materia de derechos para las minorías sexuales.

En todo caso, el arco que va de Los invertidos a El alba sobre Sodoma ilustra una transformación social y discursiva que navega entre la norma y la subversión, entre la voluntad de algunos de conservar el orden establecido y el esfuerzo de otros por impugnarlo y socavarlo. Muestra, además, que el teatro resultó un espacio significativo para dirimir problemáticas sociales coetáneas, en sintonía con la propuesta de Josep Maria Sala Valldaura:

El carácter transitivo que el teatro tiene lo vincula, pues, tanto con el eje diacrónico de la historia literaria como con el eje sincrónico. De ahí que, por un lado, se perpetúen tipos y situaciones hasta el manierismo, el pastiche, el plagio y la parodia, y que, por otro lado, el escenario se convierta también, a menudo, en laboratorio donde dirimir los temas morales del momento, fiados autor, obra y espectadores en la gran eficacia cognoscitiva y comunicativa de la ilusión teatral ${ }^{30}$.

Ciertamente, los dos ejemplos de teatro argentino presentados aquí pueden comprenderse como "laboratorios" en el sentido que propone Sala Valldaura, ya que ambos se hicieron eco de una realidad socio-sexual que atravesaba, en sus respectivos contextos históricos, una instancia decisiva de redefinición; la forma en que incorporaron a la escena esa realidad —a medio camino entre la intención moralizante y la reivindicación en Los invertidos, o mediante una inusual apología en El alba sobre Sodoma - testimonia simultáneamente las limitaciones y las posibilidades del género dramático a la hora de visibilizar, debatir y, también, transformar las siempre inestables coordenadas del género y la sexualidad.

30. "Los afectos sociales y domésticos en el teatro de Leandro Fernández de Moratín: el beso de Doña Francisca y Rita", Historia social y literatura: familia y clases populares en España (siglos XVIII Y XIX), vol. I, eds. R. Fernández y J. Soubeyroux, Saint Étienne-Lleida, Université Jean Monnet-Milenio, 2001, pp. 113-129 (113). 